Document downloaded from:

http://hdl.handle.net/10251/57694

This paper must be cited as:

Valls Ayuso, A.; García García, F.; Ramírez Blanco, MJ.; Benlloch Marco, J. (2015). A Combined Use of GPR Data With Historical Archives for Identifying Pavement Construction Periods of Valencian Silos (16th Century, Spain). IEEE Journal of Selected Topics in Applied Earth Observations and Remote Sensing. 9:1-10. doi:10.1109/JSTARS.2015.2466192.

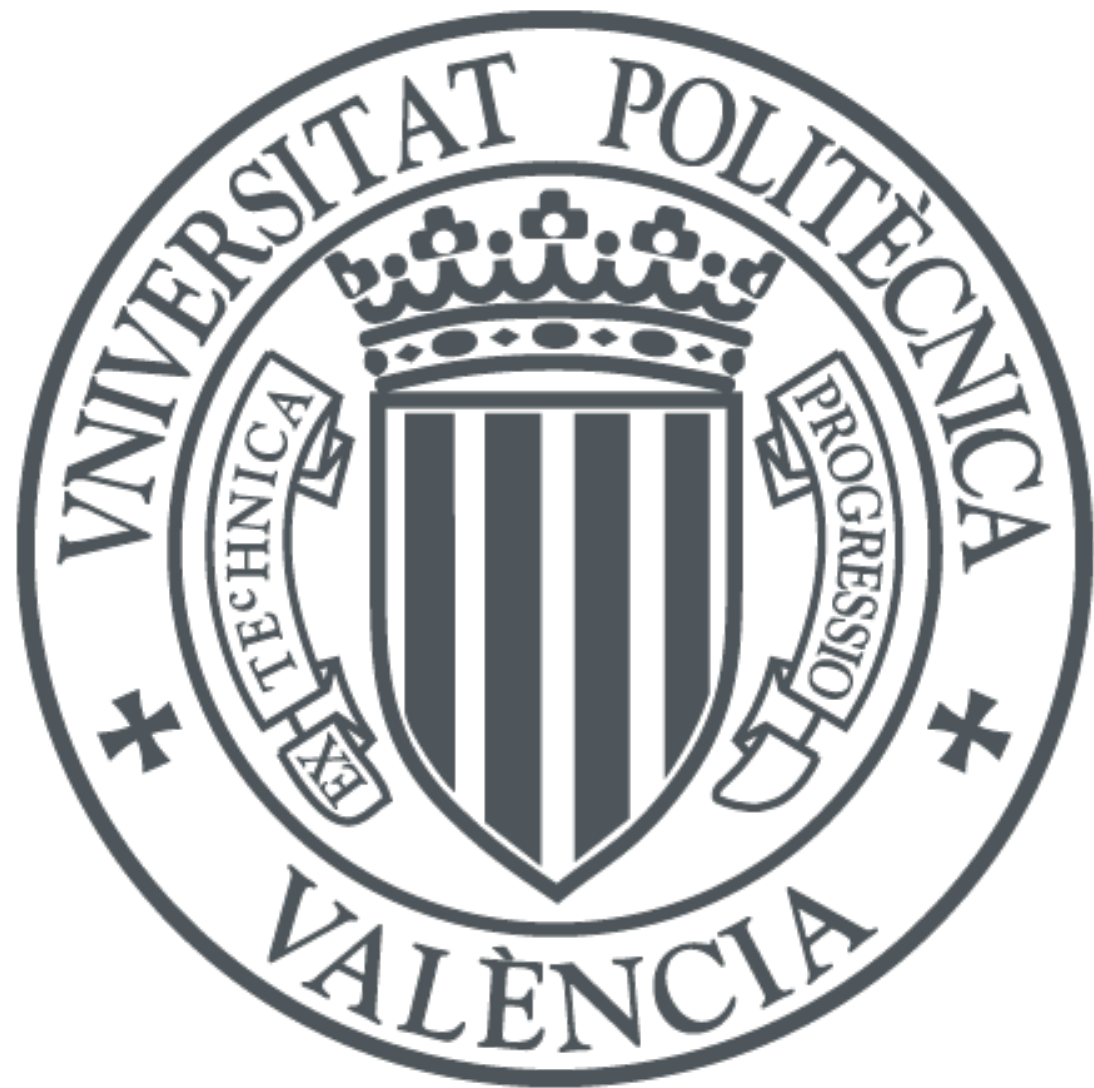

The final publication is available at

http://dx.doi.org/10.1109/JSTARS.2015.2466192

Copyright Institute of Electrical and Electronics Engineers (IEEE)

Additional Information

(C) 2015 IEEE. Personal use of this material is permitted. Permission from IEEE must be obtained for all other uses, in any current or future media, including reprinting/republishing this material for advertising or promotional purposes, creating new collective works, for resale or redistribution to servers or lists, or reuse of any copyrighted component of this work in other works. 


\title{
A combined use of GPR data with historical archives for identifying pavement construction periods of the Valencian Silos (16th century, Spain)
}

\author{
Ana Valls, Francisco García, Manuel Ramírez, and Javier Benlloch
}

\begin{abstract}
This paper describes the combined use of ground penetrating radar (GPR) data with historical archives performed in the silo-yard of Valencia (Spain) in order to identify and map various pavement construction periods.

The Valencian silos were constructed to house the underground grain storage of Valencia City. This architectural complex is composed of three buildings and a big square (siloyard), under which 41 silos are placed. The construction of the silo-yard pavement extended for two centuries (16th-18th century) following different construction systems.

Historical archives confirmed seven pavement construction periods. However, archive data provided scant information on pavement layers and the construction periods.

A GPR survey was carried out for pinpointing the seven pavement construction periods. A GSSI SIR-3000 equipment with a $400 \mathrm{MHz}$ frequency antenna was used for collecting $1 \times 1 \mathrm{~m}$ grid -141 profiles- across the square $\left(5,110 \mathrm{~m}^{2}\right)$, reaching $1,5 \mathrm{~m}$ depth. In addition, a GPS survey was performed specifically for surface mapping the silo-yard in detail.

The combined use of the GPR data (2D reflection profiles, spectra and amplitude slice maps) with the historical archives allowed identifying and delineating the different pavement construction periods on the silo-yard map in terms of materials and thicknesses.

These results demonstrate GPR is a noninvasive and nondestructive technique for mapping soils and near surface horizons. Additionally, the combined use of the GPR data with the historical documentation makes this technique even more efficient for the comprehension of shallow ground layers, especially in Cultural Heritage studies.
\end{abstract}

Index Terms-Architecture, documentation, ground penetrating radar (GPR), nondestructive testing, radar applications, spectral analysis.

This work was supported by the Valencian Government under Grant ACIF/2011/032. This paper was presented in part at the 15th Annual International Conference on Ground Penetration Radar GPR 2014, Square Brussels Meeting Centre, Brussells, Belgium, June 30-July 4, 2014.

Ana Valls, Manuel Ramírez and Javier Benlloch are with the Department of Architectural Constructions, Polytechnic University of Valencia, Camino de Vera, s/n Valencia 46022 SPAIN (e-mail: anvalay@upv.es; mramirez@csa.upv.es; jabenllo@csa.upv.es).

Francisco García is with the Department of Cartographic Engineering, Geodesy and Photogrammetry, Polytechnic University of Valencia, Camino de Vera, s/n Valencia 46022 SPAIN (e-mail: fgarciag@ upv.es).

\section{BACKGROUND}

$T$ HE Mediterranean area has a long tradition of cereal production and preservation for population subsistence. Wheat was the raw material for obtaining bread, which constituted the staple food for all social classes. During the last quarter of the 16th century, Valencia City, as the capital of the former Valencian Kingdom, was characterized by a rise in population and an economic relaunch. It had the need to storage a considerable amount of wheat so as to relieve and prevent famine. Several bonded warehouses were located in the downtown city; however, they were unsuitable for wheat preservation. Therefore, the Valencian municipality decided to build a large-scale underground grain storage on the top of a hill in a small village $5 \mathrm{~km}$ away from Valencia downtown. Geological studies proved that the ground is a clayey soil with intercalations of limestone crust substrates [1]-[3].

The Valencian silo-yard comprises a total built area of $6,175 \mathrm{~m}^{2}$ and is composed of three warehouses, a well, a small church and the 41 visible underground grain storages. Nowadays, the silo-yard is entirely paved with limestone slabs (Fig. 1).

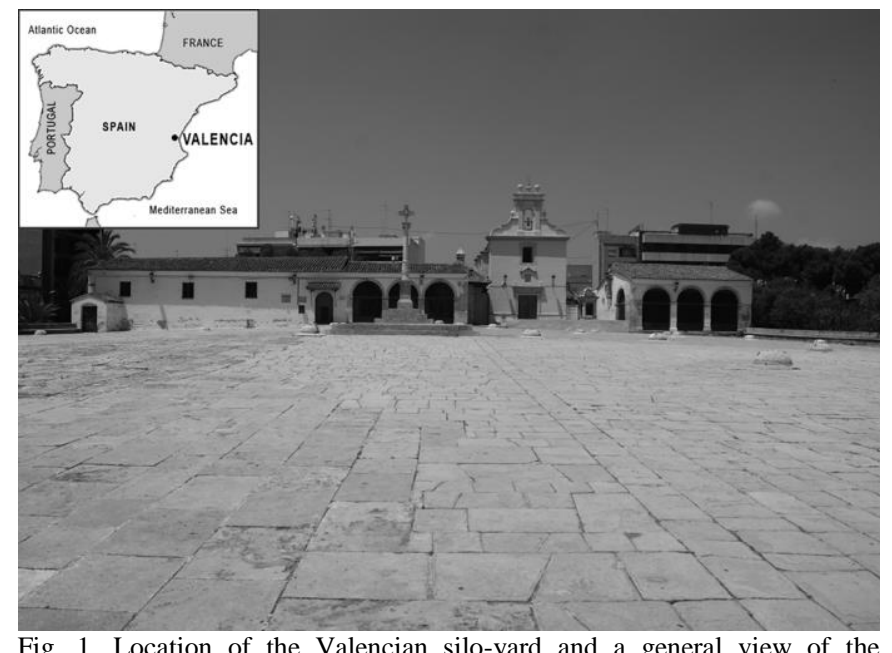

Fig. 1. Location of the Valencian silo-yard and a general view of the architectural complex entirely paved with limestone slabs. 
The historical archives specified the number of the pavement construction periods, reporting seven as the total construction periods. However, the historical data are quite incomplete in delineating each pavement construction period on a map and describing the pavement layer features.

Conventionally, construction pavement features have been determined by drilling and extracting cores from building elements. An extensive exploratory drilling program in this architectural complex would be very destructive and expensive because of the confined working space and close proximity of cavities (silos). Moreover, it only provides information on the test points. Thus, it was necessary to find a way to rationally study the pavement layers while ensuring complete coverage of the silo-yard.

On account of the need for a high-resolution survey to detect thin layers while covering as much of the site as possible, GPR technique emerged as the most viable geophysical method of measurement for studying and delineating accurately the pavement construction periods on the Valencian silo-yard map.

GPR allows imaging the subsurface. This method shows irregularities through reflections at the contacts between the materials applied in the different levels. So layers and structures at various levels within the ground can be mapped accurately. Detection and assessment of pavement layer thicknesses are frequent applications for road surveying [4][6].

In addition, GPR is recognized as a nondestructive technique for studying historical and archaeological sites and is widely used in work restoration assessment [7]-[10]. Many features of restoration work entail information on construction material thickness and state of conservation for quality control purposes [11],[12]. Layer thickness information is also needed as an input to structural assessment of historical and damaged buildings [13].

This paper describes a GPR survey carried out in the Valencian silo-yard. This architectural ensemble was declared National Historical Monument in 1982. The aim of this work was to identify and map the pavement construction periods of the Valencian silo-yard thanks to a combined use of GPR data with historical archives.

The research was carried out in three stages. Firstly, we compiled thorough historical documentation on the pavement at several historical archives. Secondly, we performed the GPR survey on the whole surface of the silo-yard in order to pinpoint the location and area of every pavement construction period. Thirdly, we analyzed and determined the electromagnetic features from different areas of the silo-yard pavement in correlation with the historical documentation. In that way, we can be properly sure that the pavement construction periods have been identified and mapped.

\section{HistoricAl ARCHIVE ANALYSIS}

The first step was to compile as much historical documentation as possible about the pavement of the Valencian silo-yard.

The majority of the information about the Valencian silo- yard pavement is gathered in the Municipal Historical Archive of Valencia. It represents the main data source and compiles files from 1573 to the last century regarding the Valencian silo-yard.

Additional information about the Valencian silos can be found in the Municipal Archive of Burjassot and in the Military Archive of Avila. As well, supplementary materials can be found in the Valencian Library and in the National Library, where there are several facsimiles including descriptions of the architectural complex. Whilst the latter archives contribute to the reconstruction of the Valencian siloyard historical evolution, they are less significant regarding the study of the pavement construction periods.

The first reference about the construction of the Valencian silos is documented in 1573, when three small pits where dug to prove their proper operation as underground granaries. From 1574 until the end of the 16th century, there is evidence of 46 silos excavated in the silo-yard. Nevertheless, during the 18th century, many silos were leveled due to ruined state of conservation and only 41 silos remained at the study site. During the 16th century, a quarter of the silo-yard surface was paved. The rest of the square was paved from $17^{\text {th }}$ to 18 th century [1]. The pavement was set on the silo-yard for waterproofing requirements and for protecting the underground silos.

Graphical records offer visual representations that are particularly useful in building up a picture of the silo-yard. However, they are incomplete and present some inaccuracies. Only two original maps of the Valencian silo complex have been kept in the Municipal Historical Archive of Valencia, so they are limited in number to render the full picture. These maps are ground layouts of the silo-yard that were drawn between 1755 and 1756 (Fig. 2). According to these graphical documents, the last four pavement construction periods were executed during the second half of the 18th century. Both maps provide evidence as to where the paved areas could be located at that time. Nonetheless, they are insufficiently comprehensive in themselves and need to rely on complementary sources, such as handwritten records.

Manuscripts comprise information about four centuries, but this study was restricted to the documents pertaining to 16 th, 17 th and 18th centuries. Handwritten documents provided useful data for confirming seven pavement construction periods, but they offered scant information on their areas and construction features. Some pavement construction period features extracted from the historical documentation are summarized in Table 1.

The data obtained from the historical archives give an idea of the approximate location and area of the pavement construction periods of the Valencian silo-yard (Fig. 3).

\section{GPR SURVEY DETAILS AND PROCESSING}

The second step of the study was to perform the GPR survey on the whole surface of the silo-yard.

The GPR analysis of the Valencian silo-yard was performed using a GSSI SIR-3000 equipment and a $400 \mathrm{MHz}$ centerband frequency antenna with $50 \mathrm{~ns}$ time window. Also, a GPS 

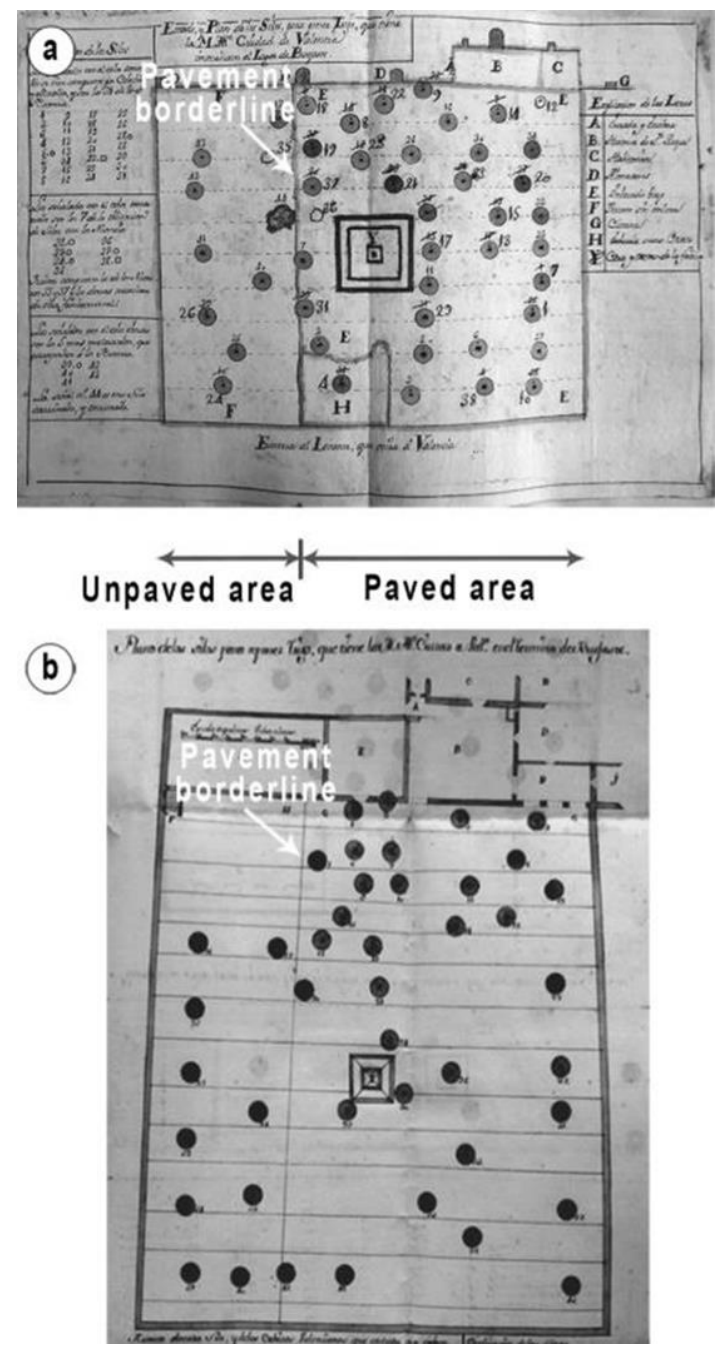

Fig. 2. Two historical maps dated from 1755 (a) and 1756 (b), where the paved and unpaved areas are delineated without specifying the location of the pavement construction periods.

survey was performed specifically for determining the dimensions of the silo-yard surface and georeferencing the GPR profiles.

Data collection was required to cover the whole silo-yard surface $\left(5,110 \mathrm{~m}^{2}\right)$. A $1 \times 1 \mathrm{~m}$ grid of 141 orthogonal profiles was collected (Fig. 4). Following data acquisition, all profiles were processed and analyzed using RADAN software (GSSI). Although raw data revealed several anomalies, data processing stages were applied, such as the correction of time-zero to match with the pavement surface level. The application of migration filter allowed the dipping layers correction and the diffraction remove. Finally, in order to augment significant reflection and improve the anomaly identification, some type of gaining function was applied.

A spectral analysis and several amplitude slice maps were obtained for pinpointing the location and boundaries of the pavement construction periods of the silo-yard.

The soil where the silo-yard was placed is a homogeneous material: clayey soil with intercalations of limestone crusts substrates. Owing to the existence of tunnels connecting some of the subterranean silos, the distance between the inner surfaces of contiguous silos was known. So the distance (h) was measured. The dielectric permittivity $(\varepsilon)$ was calculated to be 8 , according to the following equation [14]-[16]:

$\varepsilon_{\mathrm{r}}=\left(\frac{\mathrm{c}}{\mathrm{v}}\right)^{2}=\left(\frac{\mathrm{ct}}{2 \mathrm{~h}}\right)^{2}$

where $\mathrm{h}$ is the depth, $\mathrm{t}$ is the two-way travel time, $\mathrm{v}$ is the electromagnetic wave velocity and $\mathrm{c}$ is the velocity of light in free space $(\mathrm{c} \approx 3 \times 108 \mathrm{~m} / \mathrm{s})$.

All the time windows were converted to depth using this dielectric permittivity. To convert time scale to depth, the subsurface electromagnetic wave velocity was obtained from $\varepsilon$ [14],[15]:

$\mathrm{v}=\frac{2 \cdot \mathrm{h}}{\mathrm{t}}$

The average velocity of the GPR wave was estimated to be $10.6 \mathrm{~cm} / \mathrm{ns}$. This information was contrasted with $\mathrm{v}$ and $\varepsilon$ values of dry clay-filled and limestone substrates that have

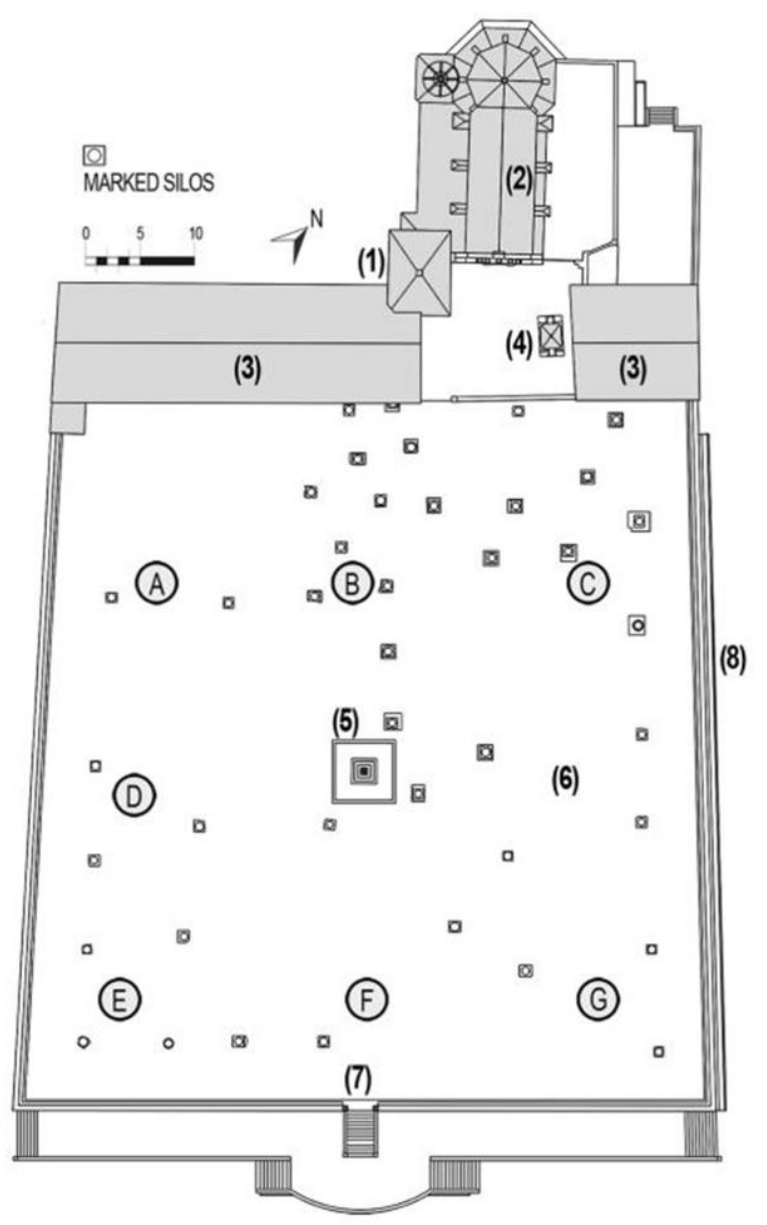

Fig. 3. Hypothetical locations (A to G) of the seven pavement construction periods derived from historical archive research. The Valencia silo complex consist of: (1) Main entrance (16th c.), (2) Chapel, (3) Warehouses, (4) Well, (5) Greek cross sculpture, (6) Silo-yard, (7) Secondary entrance (19th c.), (8) Wall. 
TABLE 1

PAVEMENT CONSTRUCTION FEATURES OBTAINED FROM HistoricAl ARCHIVES AND GPR SURVEY DATA

\begin{tabular}{|c|c|c|c|c|c|c|c|c|c|c|c|c|c|c|c|c|}
\hline \multirow{3}{*}{$\begin{array}{c}\text { Pavement } \\
\text { construction } \\
\text { periods } \\
\text { (years) }\end{array}$} & \multicolumn{7}{|c|}{ SILO ARCHIVE DATA } & \multicolumn{9}{|c|}{ SILO GPR DATA } \\
\hline & \multirow{2}{*}{$\begin{array}{c}\text { Area } \\
\left(\mathrm{m}^{2}\right)\end{array}$} & \multicolumn{2}{|c|}{ Slabs } & \multicolumn{2}{|l|}{ Mortar } & \multicolumn{2}{|c|}{ Filling materials } & \multicolumn{3}{|c|}{ Slabs } & \multicolumn{3}{|c|}{ Mortar } & \multicolumn{3}{|c|}{ Filling materials } \\
\hline & & Material & $\begin{array}{c}\mathbf{h} \\
(\mathrm{cm})\end{array}$ & Material & $\begin{array}{c}\mathbf{h} \\
(\mathrm{cm})\end{array}$ & Material & $\begin{array}{c}\mathbf{h} \\
(\mathrm{cm})\end{array}$ & $\mathbf{V}(\mathrm{cm} / \mathrm{ss})$ & $\varepsilon_{\mathrm{r}}$ & $\mathbf{h}(\mathrm{cm})$ & $\underset{(\mathrm{cm} / \mathrm{ss})}{\mathbf{v}}$ & $\varepsilon_{\mathrm{r}}$ & $\mathbf{h}(\mathrm{cm})$ & $\underset{(\mathrm{cm} / \mathrm{ss})}{\mathbf{v}}$ & $\varepsilon_{\mathrm{r}}$ & $\begin{array}{l}\mathbf{h}_{\max } \\
(\mathrm{cm})\end{array}$ \\
\hline $1580-1583$ & $1,508.25$ & Limestone & - & - & - & Mud, lime, sand & - & 10.6 & 8 & 18.5 & 8 & 14 & 6 & 17.5 & 2.9 & 95 \\
\hline $\begin{array}{c}\text { 1590-1620 } \\
\text { (approx.) }\end{array}$ & - & Limestone & - & - & - & - & - & 10.7 & 7.8 & 18.7 & 8.1 & 13.7 & 6.1 & 18.7 & 2.5 & 110 \\
\hline 1705-1706 & $\begin{array}{c}102 \\
\text { (approx.) }\end{array}$ & Limestone & - & - & - & - & - & 11.3 & 7 & 15.3 & 8.3 & 13 & 7.5 & 19.7 & 2.3 & 98 \\
\hline 1755 & 147.126 & Limestone & 22.4 & Lime, sand & 17 & - & - & 11.2 & 7.2 & - & 7.6 & 15.5 & - & 21 & 2 & 115 \\
\hline $1770-1772$ & 711 & Limestone & 16.7 & Lime, sand, gravel & 22.60 & - & - & 11.1 & 7.3 & - & 8.2 & 13.4 & - & 24 & 1.5 & 120 \\
\hline 1783 & 526.13 & Limestone & 16.5 & - & - & - & - & 11 & 7.4 & - & 7.8 & 14.7 & 7 & 16.2 & 3.4 & 105 \\
\hline $1787-1788$ & 387.61 & Limestone & 16.5 & - & - & - & - & 11 & 7.4 & - & 7.9 & 14.4 & 7.9 & 22 & 1.8 & 115 \\
\hline
\end{tabular}

been reported by several authors [14]-[19]. Radargram profiles were represented with distance parameters on $\mathrm{dx}$ and depth parameters on dy.

This method was also applied to reveal the pavement layer thicknesses. The historical information was used to attain reliable pavement layer thickness estimation by interpreting the GPR data. We first obtained preliminary data for the pavement construction periods in which the material thicknesses below the surface were known. The depth of the pavement layers and the two-way travel time were used to estimate the electromagnetic wave velocity in various materials. The dielectric permittivity of the different pavement materials was obtained using the Equation (1) (Table 1).

Fig. 5 shows a reflection profile and the interpreted data for the shallow layers that form the pavement area built from 1770 to 1772 . The contact between the flagstones and the mortar is known at a depth of $16.7 \mathrm{~cm}$ and the contact between the mortar and the filling materials is also known at about 40 $\mathrm{cm}$ depth (Table 1). We can observe the coupling reflection between the air wave and the flagstone surface (a), and the contact between the limestone slabs and the mortar (b). The contact between the mortar and the filling materials is also identified by the reflection caused by the change in the electromagnetic wave velocity (c).

When there was a lack of information about pavement layer thicknesses in historical documents the velocity and permittivity were obtained by using hyperbolic events. We calculated the average velocity of the travel wave in the medium using the hyperbola equation [20]:

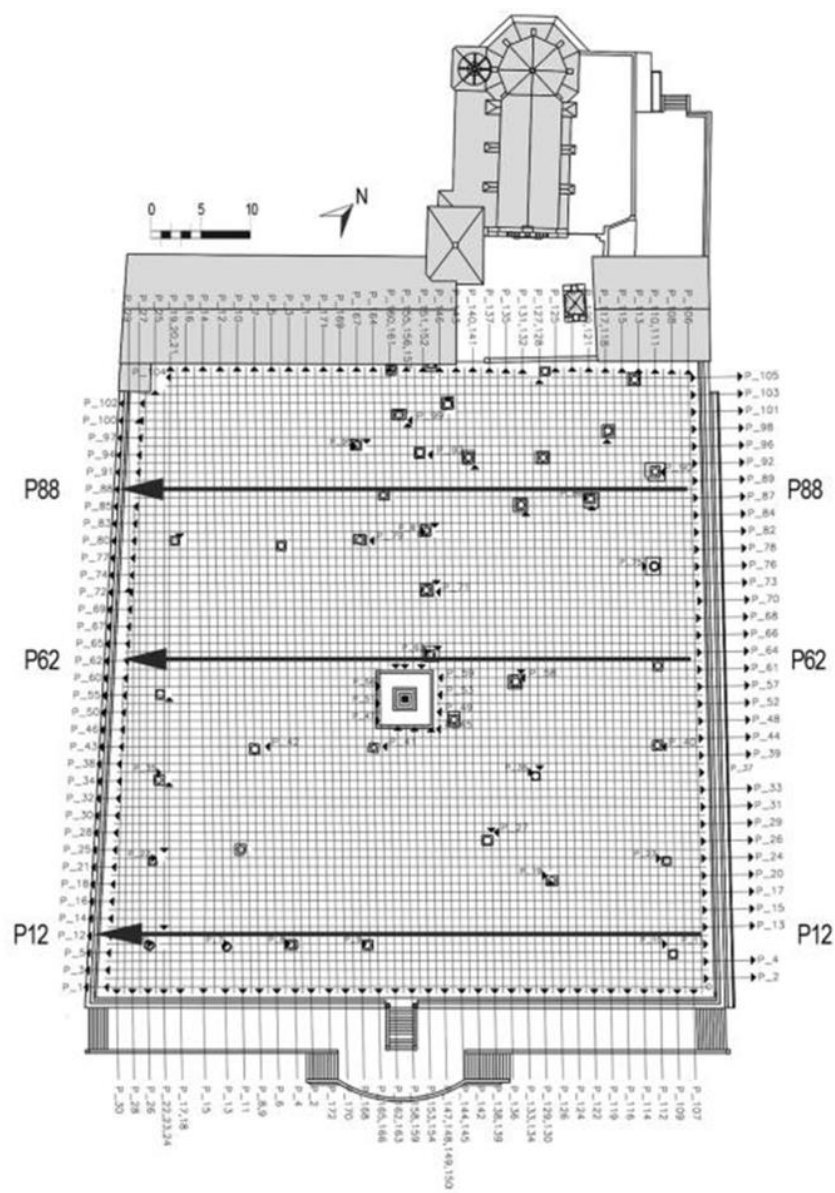

Fig. 4. Location of GPR reflection profiles collected at the silo-yard with a $400 \mathrm{MHz}$ center frequency antenna. 

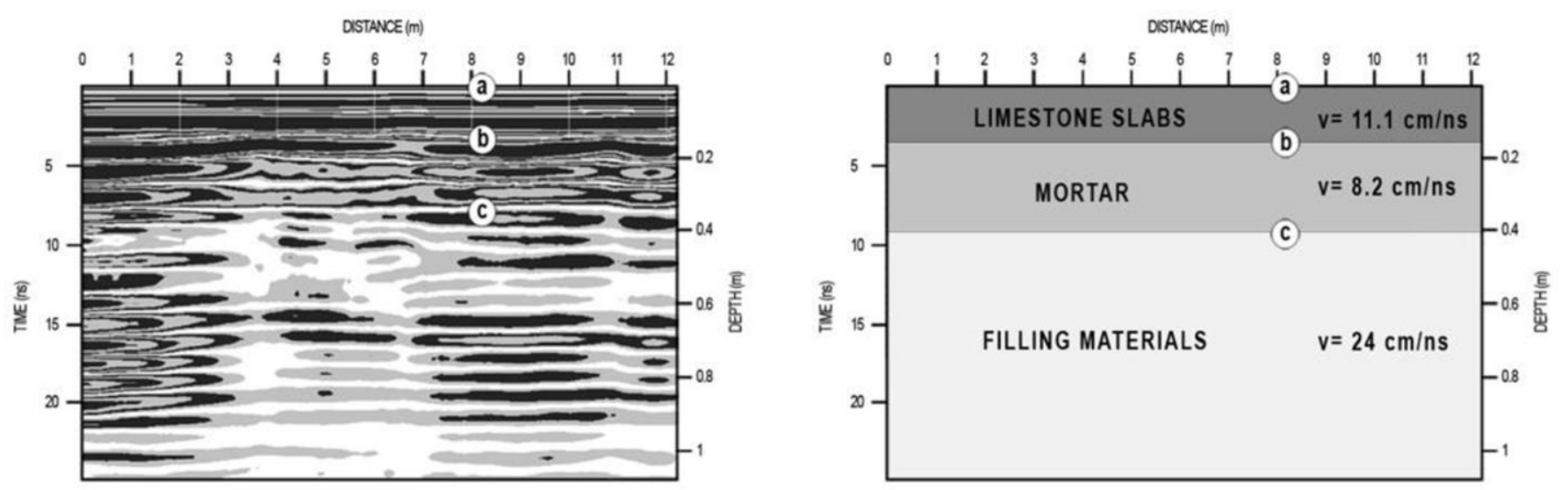

Fig. 5. Radar data and interpretation of the P44 reflection profile where are shown: (a) the coupling reflection between the air wave and the flagstone surface, (b) the contact between the limestone slabs and the mortar layer and (c) the reflection of the contact between the mortar and the filling materials. The velocity can be obtained from known thicknesses of pavement layers (from historical archives) and the two-way travel time to the reflective sheet. The velocity of filling materials was obtained using the hyperbola equation.

$\mathrm{t}^{2}=\frac{4}{v^{2}} d^{2}+t_{0}^{2}$

where $\mathrm{t}$ is the two-way travel time, $\mathrm{v}$ is the wave average velocity, $\mathrm{t}_{0}$ is the two-way travel time to the apex of the hyperbola and $\mathrm{d}$ the distance. Different points on the hyperbola were taken and related to the two-way travel time of the electromagnetic waves to plot $\mathrm{t}^{2}$ as a function of $\mathrm{d}^{2}$. So a straight line was obtained by fitting the points.

The velocity and permittivity values were also compared with the values reported by other authors [14]-[19]. In the limestone slabs, the velocities ranges from $10.6 \mathrm{~cm} / \mathrm{ns}\left(\varepsilon_{\mathrm{r}}=8\right)$ in the paved area made on 1580 to $11.3 \mathrm{~cm} / \mathrm{ns}\left(\varepsilon_{\mathrm{r}}=7\right)$ in the paved area built on 1705. In the mortars, the average velocities were between $7.6 \mathrm{~cm} / \mathrm{ns}\left(\varepsilon_{\mathrm{r}}=15.5\right)$ in the mortar used on 1755 to $8.3 \mathrm{~cm} / \mathrm{ns}\left(\varepsilon_{\mathrm{r}}=13\right)$ in the mortar utilized on 1705 . Regarding the filling materials, the velocities were approximately between $16.2 \mathrm{~cm} / \mathrm{ns}\left(\varepsilon_{\mathrm{r}}=3.4\right)$ and $24 \mathrm{~cm} / \mathrm{ns}\left(\varepsilon_{\mathrm{r}}=1.5\right)$. The velocity and permittivity values of the silo-yard pavement construction periods are shown together with historical data in Table 1.

\section{DATA INTERPRETATION AND ANALYSIS}

The third step was to analyze the radar data and the electromagnetic features from the silo-yard pavement in correlation with the historical archives.

The GPR survey performed at the silo-yard revealed the pavement layers and corroborated the historical documentation obtained from the archives. Three horizons were detected over the natural terrain. The superficial layers were limestone slabs over a mortar layer; and the deeper level was variable-thickness filling materials over the natural terrain (Fig. 6). The layer interfaces could be identified successfully when the contrast between the dielectric properties of the pavement layers was significant.

A good illustration of typical reflection profiles collected in the silo-yard is shown in Fig. 7(a) profile P88, (b) profile P62 and (c) profile P12. These radargrams evidence the floor strata and the different construction periods of the silo-yard pavement. The reflections at two pavement periods interface and the differential compaction of the filling materials were the keys to delimitate the pavement construction periods when analyzing the reflection profiles. Lateral changes were caused by shallow hyperbolic diffractions in correspondence with the position of the mortar joints between the different pavement construction periods. These anomalies are shown in Fig. 7(a) at meters 38 and 46, in Fig. 7(b) at meters 38 and 46 and in Fig. 7(c) at meters 34 and 48.

\section{A. Limestone slabs}

The radargrams obtained along the silo-yard clearly shows a horizontal, variable-amplitude reflection from the border between the slabs and the mortar layer, at a two-travel time between $2.7 \mathrm{~ns}$ and $4 \mathrm{~ns}$ from the surface (depending on the pavement construction period).

Relatively constant values were obtained from the velocity

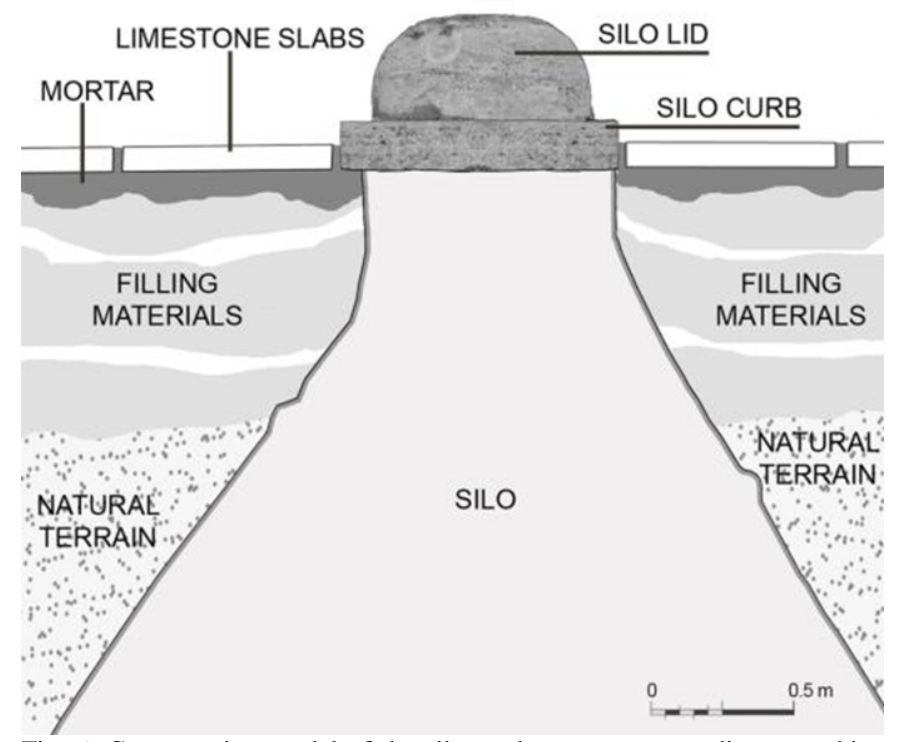

Fig. 6. Cross section model of the silo-yard pavement according to archive data and corroborated by GPR data interpretation. 
(a)

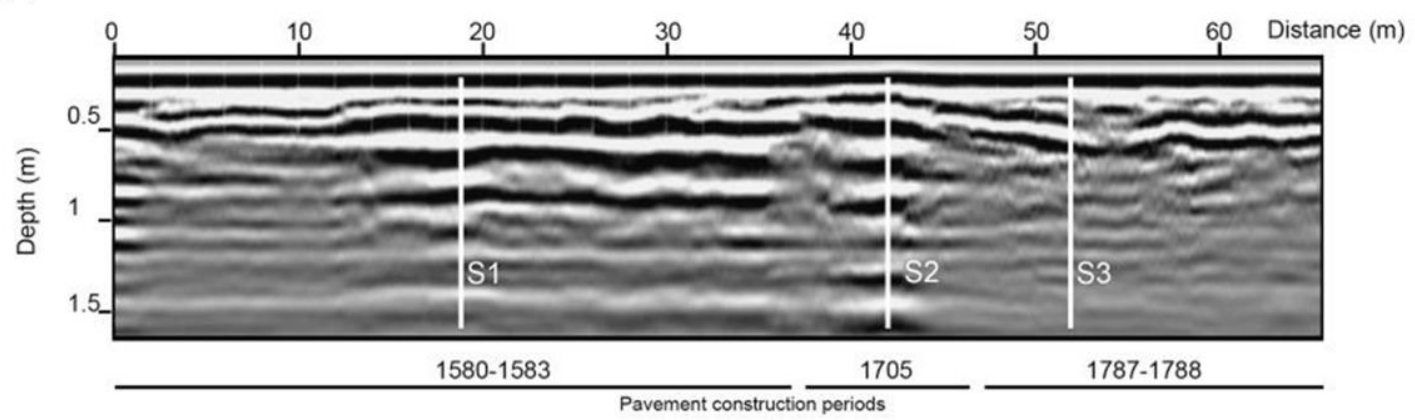

(b)

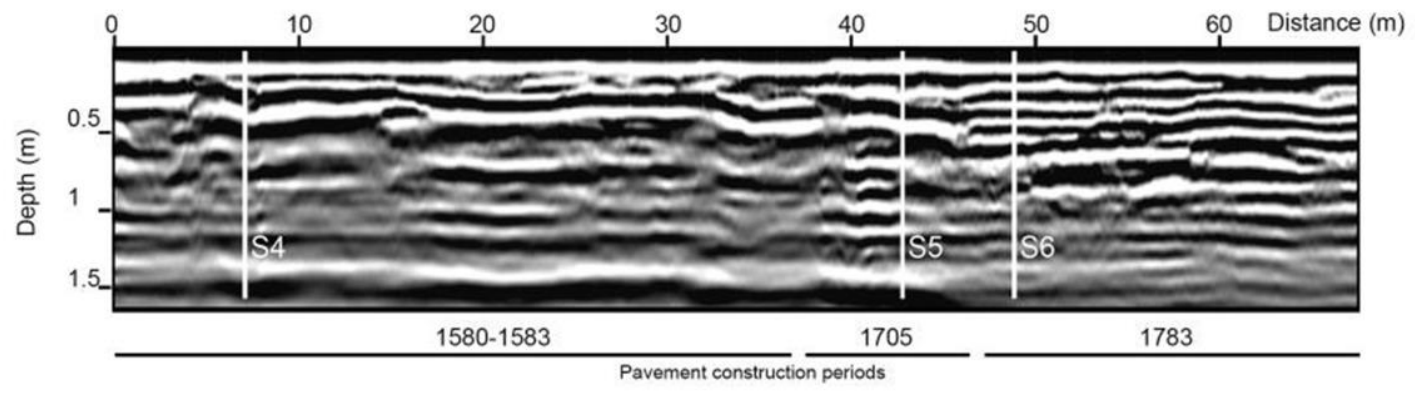

(c)

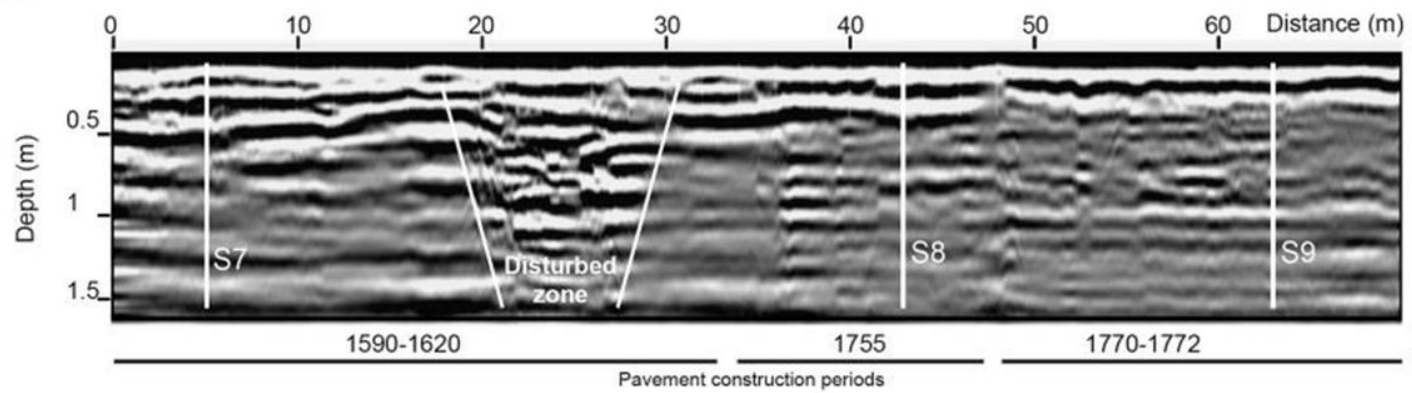

Fig. 7. Selected reflection profiles P88 (a), P62 (b) and P12 (c), obtained with $400 \mathrm{MHz}$ center frequency antenna. These reflection profiles include the seven pavement construction periods confirmed by the historical archives. A spectral analysis of nine set of traces (S1 to S9) was carried out.

analysis along the limestone slabs. Slight variations on wave velocity and dielectric permittivity values were probably caused by different degrees of eroding and cracks of the limestone slabs (Fig. 8).

\section{B. Mortar layer}

Limestone slabs were placed over a variable-thickness mortar layer. The mortars were usually made of lime, sand, water and, occasionally, gravel in different proportions. The heterogeneous constitution of the mortar layer is supported by the presence of weak diffraction hyperbolas. The GPR data identified anomalies produced by sharp variations in wave velocity at the contact between the different construction layers. Reflections at between $4.5 \mathrm{~ns}$ to $8.5 \mathrm{~ns}$ (from the surface) correspond to the boundary between mortar layer and deeper inhomogeneous layer (filling materials) (Fig. 7).

Differences between thicknesses of the mortar layers are recognized in each pavement construction period. Fig. 7(c) shows GPR measurements acquired on the pavement construction period from 1770-1772, from meter 48 to meter 70. The main feature that difference this paved area from the rest of the silo-yard was the thicker mortar layer of more than $22 \mathrm{~cm}$ thick. A slight and irregular mortar layer was identified beneath the limestone slabs between meter 38 and meter 46 in Fig. 7(a) and 7(b). Wave velocity and dielectric permittivity values of the paved area built between 1705 and 1706 reveal the increase of the porosity measured in dry basis (Table 1).

\section{Filling materials}

The lowest stratum of the pavement consisted of filling materials, clayey compacted layers with mortar and water. Strong diffraction hyperbolas mark the heterogeneity of this stratum. Time fluctuations of the back surface of the stratum highlight velocity variation due to different material characteristics.

The aim of the filling material analysis was to identify the 


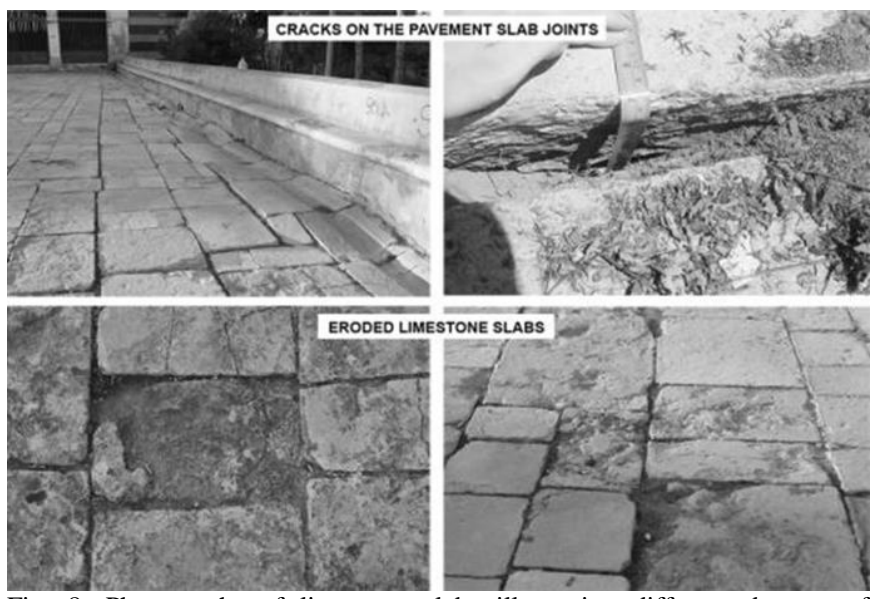

Fig. 8. Photographs of limestone slabs illustrating different degrees of eroding and cracks.

level of soil compaction and to detect possible buried components that could damage the silo-yard pavement. Hyperbolic reflections appear in some of the profiles collected in the silo-yard. A zone categorized "disturbed zone" in profile P12 in Figure 7(c) suggests the presence of filling materials that were used to fill in a silo and level the surface. Its depth at $0.25 \mathrm{~m}$ and dimension, from meter 20 to meter 28 , suggests the presence of an underground granary. It is therefore probable that insufficient compaction in some part of the filling materials can be the cause of the largest cracks on the pavement slab joints (Fig. 8).

Regarding the velocity analysis on the filling materials, variations were found according to the different materials and level of compaction, as shown in Table 1 . The paved area represented in Fig. 7(b) from meter 46 to meter 70 could be considered the best executed pavement of the silo-yard. In this particular case, the filling materials consist of several thin compacted layers. Velocity and permittivity values in this area are indicative of an elevated level of soil compaction and low porosity in dry conditions.

Additionally, a spectral analysis was applied to each suspected paved area detected on the site [21]. A spectrum can be defined as the whole range of electromagnetic radiation with respect to its frequency. The reaction of GPR radiation is different for each material and so it is the range of the operating frequency band. The frequency bandwidth and the central antenna frequency peak vary throughout data compilation. Hence, spectral analysis could be used as a complementary recognition tool for subsurface anomaly identification. With this purpose, the spectra of several radargram traces have been analyzed in this research. These spectra correspond to each paved area detected on the siloyard.

The soil of the site was a homogeneous material: clayey soil with intercalations of limestone crusts substrates. So the variation in the electromagnetic signal could only be caused by the different pavement layer features. Due to relatively constant values from the velocity analysis along the limestone slabs and the mortar layers, the signal variation could be largely attributed to the filling materials.
In Fig. 9(a) three spectra of three set of traces are illustrated. Each spectrum is an example of the signal response in different pavement construction periods. Great peaks of energy were obtained over 160-200 (S1 spectrum), 240 (S2 spectrum) and $350 \mathrm{MHz}$ (S3 spectrum) when the pavement construction periods dated from 1580-1583, 1705-1706 and 1787-1788 were detected. However, minor peaks were obtained at 120, 310 and $380 \mathrm{MHz}$ (S1 spectrum); 150 and $380 \mathrm{MHz}$ (S2 spectrum); and 180 and $240 \mathrm{MHz}$ (S3 spectrum).

The predominant frequency bandwidth ranges from 100 to $410 \mathrm{MHz}$. However, we find a high amplitude peak around $410 \mathrm{MHz}$ and minor peaks at 170,230 and $320 \mathrm{MHz}$ (S6 spectrum, Fig. 9 (b)). In Fig. 9(c) again three spectra of three different set of traces are depicted. In this case, the main amplitude peaks were identified at 180 (S7 spectrum), 240 (S8 spectrum) and $330 \mathrm{MHz}$ (S9 spectrum), in correspondence with the pavement construction periods dated from 15901620, 1755 and 1770-1772. Minor peaks are also illustrated in the range of the frequency bandwidth between 110 and 410 $\mathrm{MHz}$.
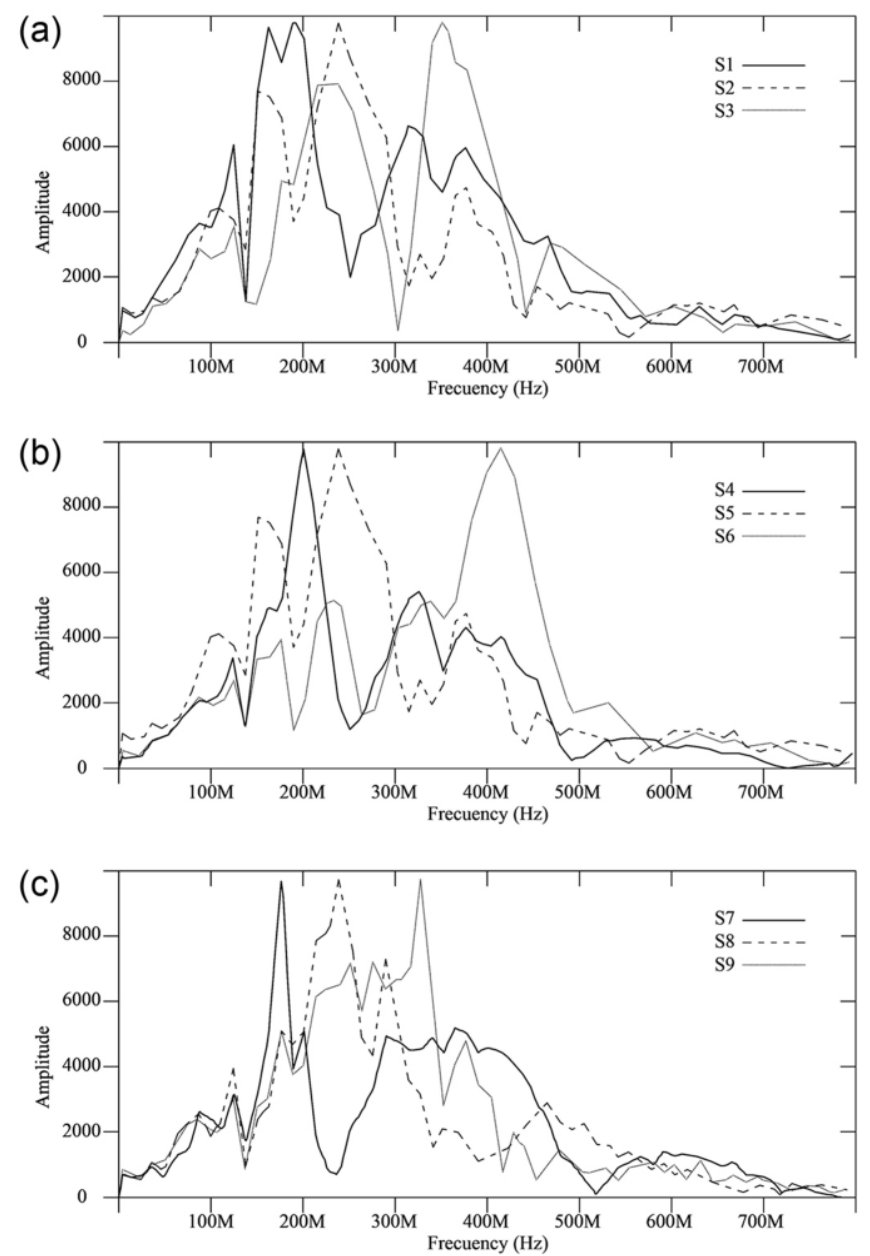

Fig. 9. Spectral analysis of nine set of traces (S1 to S9) belonging to the P88 (a), P62 (b) and P12 (c) reflection profiles. S1 and S4: construction period dated from 1580-1583, S2 and S5: construction period dated from 17051706, S3: construction period dated from 1787-1788, S6: construction period dated from 1783, S7: construction period dated from 1590-1620, S8: construction period dated from 1755, S9: construction period dated from 1770-1772. 

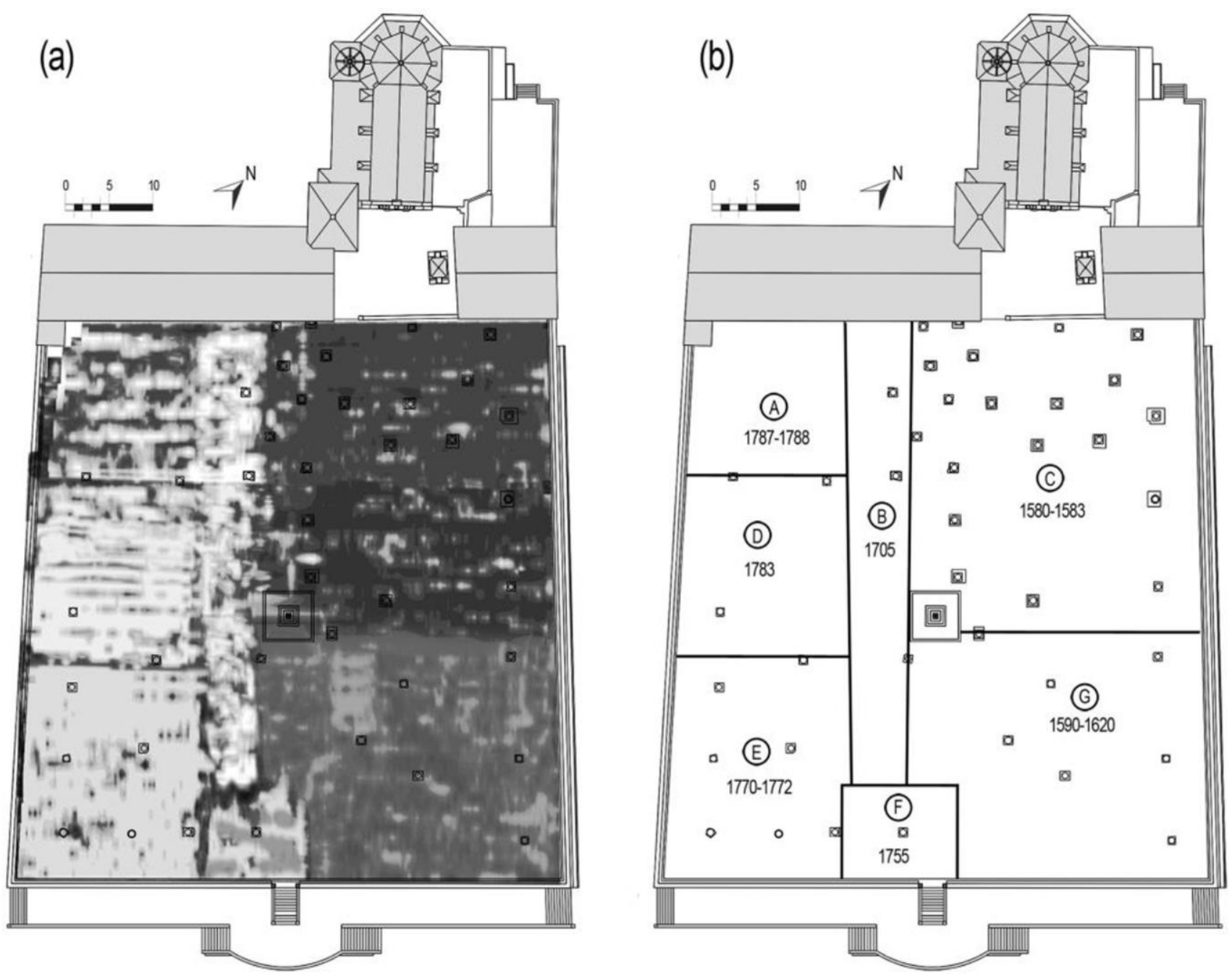

Fig. 10. Silo-yard maps for the location of the seven pavement construction periods. (a) Amplitude slice map of the silo-yard at $0.30 \mathrm{~m}$ depth. (b) Delineation of the seven pavement construction periods (A to $G$ ) on the silo-yard map as a result of the combined use of GPR data with historical archives.

In the spectral analysis of these radargrams we noticed that the spectra behavior when considering traces that correspond to each pavement construction period is completely different. The displacement of the outstanding amplitude peaks might be in correlation with differential compaction filling materials.

The absence of correspondence between the spectra can be interpreted as a sample that distinguishes the spectral response of the different layers that compose each pavement construction period of the silo-yard.

The GPR reflections were also visualized in amplitude slice maps [22]. An amplitude map of the silo-yard subsurface was made up to complement the spatial correlation of radargrams and different paved area spectra. This representation allows better appreciating the pavement spatial relationships. The slice display shown in Fig. 10(a) is a visualization of the more relevant subsurface features at $0.30 \mathrm{~m}$ depth. Limestone slabs and mortar layers were omitted and the amplitude slice map showed the different filling materials associated to each pavement construction period. In the slice display there is a strong correspondence between the boundary locations of the different paved areas and the subsurface reflections visible in the 2D GPR reflection profiles. Each pavement construction period shows different amplitude reflections.

The combined use of the results derived from GPR survey (2D reflection profiles, spectra and amplitude slice maps) with historical data allowed us to confirm the delineation of the seven pavement construction periods on the silo-yard map, Fig. 10(b).

\section{CONCLUSION}

As a result of our archive research seven different pavement construction periods were documented at the Valencian siloyard. However, there were unanswered questions concerning the location and the boundaries of each pavement construction period.

The historical significance of the study site was a determinant factor for rejecting the application of a conventional drilling program. So a nondestructive technique appeared to be the most viable method. We used GPR as an extensive and high-resolution method for covering the whole study area, with the assistance of a GPS survey for 
determining the dimensions of the silo-yard surface and georeferencing the GPR profiles.

We carried out a comprehensive research on the historical information from the Valencian historical archives and libraries. Manuscripts confirmed seven pavement construction periods, but 18th-century maps were inexplicit. So the GPR technique was used for delineating pavement construction features of the silo-yard.

We used radar data to detect the pavement layers of each construction period on the silo-yard and confirm the historical data from the archives. We obtained wave velocities from the pavement layers of each construction period to guarantee accurate interpretations. Wave velocity values were relatively constant along the limestone slabs (approximately $11 \mathrm{~cm} / \mathrm{ns}$ ) and the mortar layers (approximately $8 \mathrm{~cm} / \mathrm{ns}$ ). So the reflection features in filling materials allowed the differentiation of one pavement construction period from another.

Radar data spectral analysis was conclusive to corroborate the historical documentation about pavement construction periods. Each pavement period presented a different spectral response with amplitude peaks that ranges from 160 to 410 MHz. As it is also revealed in this study, spectral analysis was successfully applied for differential compaction of filling material recognition.

The amplitude slice map emerged as a useful and effective tool in imaging shallow layers at various levels. Different subsurface zones were mapped, which may correspond to each of the seven pavement construction periods of the silo-yard. Although in the 2D reflection profiles the interfaces between pavement construction periods and the differential compacted materials were already observed, the amplitude slice map was conclusive in pinpointing their boundaries on the silo-yard surface.

The location of the seven construction periods on the siloyard also let us conclude that the site was paved clockwise, starting in the NW corner and finishing in the SW side, probably because of a more intense use of the eastern and central spaces.

These results show GPR technique is a significant and suitable sensing technique for shallow layer detection, especially when conventional drilling program becomes an impossible task. In this case study, the combination of GPR data with historical documents has been crucial for solving important question marks concerning the historical building process of the Valencian silo-yard pavement.

The combined use of the GPR data with the historical documentation makes this geophysical technique even more efficient for understanding and delineating construction processes on shallow layers and structures, especially in Cultural Heritage research.

\section{ACKNOWLEDGMENT}

The authors would like to thank Valencia and Burjassot city councils for letting us carry out this research of the Valencian Silos, as well as to the Municipal Historical Archive of Valencia for the attention and helpful suggestions.

\section{REFERENCES}

[1] A. Valls, Silos de Burjassot (S. XVI). Origen y desarrollo constructivo. Evolución de sus estructuras. Estado de conservación, $\mathrm{PhD}$ thesis, Valencia (Spain): Polytechnic University of Valencia, 2014.

[2] L. Expósito. Los Silos de Burjassot: el granero de Valencia, Valencia: Instituto Municipal de Juventud de Burjassot, 2005.

[3] J. Miret, Sistemes tradicionals de conservació dels aliments en fosses i sitges. Un enfocament multidisciplinary, Barcelona, 2009.

[4] A. Loizos, C. Plati, "Accuracy of pavement thicknesses estimation using different ground penetrating radar analysis approaches," $N D T \& E$ International, 40(2), pp. 147-157, 2007.

[5] J. M. Simonin, et al. "Case study of detection of artificial defects in an experimental pavement structure using 3D GPR systems," Ground Penetrating Radar (GPR), 2014 15th International Conference on. IEEE, 2014.

[6] T. Saarenketo, T. Scullion. "Road evaluation with ground penetrating radar," Journal of applied geophysics, 43(2), pp.119-138, 2000.

[7] L.B. Conyers, "Innovative ground-penetrating radar methods for archaeological mapping," Archaeological Prospection, 13, pp. 139-141, 2006.

[8] G. Barone, C. Branca, S. Gresta, S. Imposa, A. Leone, D. Majolino, "Geoarcheometric and geophysical methodologies applied to the study of cultural heritage: "St. Agata la Vetere" in Catania (Sicily, Italy)," Journal of Cultural Heritage, 5, pp. 263-271, 2004.

[9] M. De la Vega, A. Osella, E. Lascano, J.M. Carcione, "Ground penetrating radar and geo-electrical simulations of data from the Floridablanca archaeological site," Archaeological Prospection, 12, pp. 19-30, 2005.

[10] V.P. Gracia, J.A. Canas, L.G. Pujades, J. Clapés, O. Caselles, F. García, R. Osorio. "GPR survey to confirm the location of ancient structures under the Valencian Cathedral (Spain)," Journal of Applied Geophysics, 43(2), pp. 167-174, 2000.

[11] D. Ranalli, M. Scozzafava, M. Tallini, "Ground penetrating radar investigations for the restoration of historic buildings: the case study of the Collemaggio Basilica (L'Aquila, Italy)," Journal of Cultural Heritage, 5, pp. 91-99, 2004.

[12] N. Masini, L. Nuzzo, E. Rizzo. "GPR investigations for the study and the restoration of the rose window of Troia Cathedral (southern Italy)," Near Surface Geophysics, 5(5), pp. 287-300, 2007.

[13] M. Ramírez-Blanco, F. García-García, I. Rodríguez-Abad, R. MartínezSala, J. Benlloch. "Ground-penetrating radar survey for subfloor mapping and analysis of structural damage in the Sagrado Corazón de Jesús Church, Spain," Archaeological Prospection, 15(4), pp. 285-292, 2008.

[14] V. Pérez, Radar del subsuelo, Evaluación en arqueología y en patrimonio histórico-artístico, $\mathrm{PhD}$ thesis, Barcelona (Spain): Polytechnic University of Catalonia, 2001.

[15] F. García, Aplicaciones de la técnica geofísica de prospección por georadar en ingeniería civil y glaciología, $\mathrm{PhD}$ thesis, Barcelona (Spain): Polytechnic University of Catalonia, 1997.

[16] L.B. Conyers, Ground-penetrating radar for archaeology, UK: AltaMira Press, 2013.

[17] D.J. Daniels, Ground Penetrating Radar, second ed. IEE, UK, 2004.

[18] J. Davis, A. Annan, "Ground-penetrating radar for high resolution mapping of soil and rock stratigraphy," Geophysics Prospection, 37, pp. $531-551,1989$.

[19] V.N. Kobranova, Petrophysics, Mir Publishers Moscow, 1989.

[20] V. Pérez-Gracia, F. García, L.G. Pujades, R.G. Drigo, D. Di Capua. "GPR survey to study the restoration of a Roman monument," Journal of Cultural Heritage, 9(1), pp. 89-96, 2008.

[21] F.García García, M.Ramírez Blanco, I.Rodríguez Abad, R.Martínez Sala, I. Tort Ausina, J.Benlloch Marco, J.L. Montalvá Conesa, "GPR technique as a tool for cultural heritage restoration: San Miguel de los Reyes Hieronymite Monastery, 16th century (Valencia, Spain)," Journal of Cultural Heritage, 8(1), pp. 87-92, 2007.

[22] L.B. Conyers, Interpreting ground-penetrating radar for archaeology, USA: Left Coast Press, 2012. 


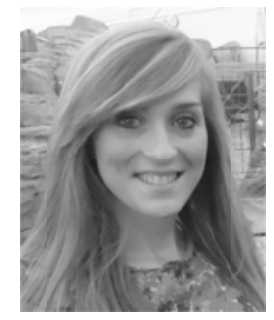

Ana Valls was born in Valencia (Spain), in 1986. She received the B.S. degree in architecture, in 2010, the M.S. in preservation of architectural heritage, in 2013 and the Ph.D. degree in architecture and urban planning, in 2014, from the Polytechnic University of Valencia, Spain.

From 2011, she has been a Research Assistant with the Department of Architectural Constructions, Polytechnic University of Valencia. Her research interest includes cultural heritage, NDT and subterranean architecture.

Dr. Valls' awards and honors include the fellowship from the Valencian Government (ACIF/2011/032) and the National Best Record Award in 2013.

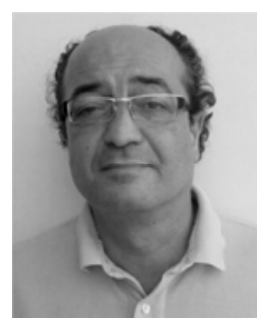

Francisco García was born in Valencia (Spain), in 1965. He received the B.S. degree in Geophysical Engineering from the Moscow Geological Prospecting Institute, Russia (former USSR), in 1991, the M.S. in Earthquake Engineering and Structural Dynamics, in 1994 and the Ph.D. degree in Civil Engineering, in 1997 from the Polytechnic University of

Catalonia, Spain.

Since 2007, he has been a Professor with the Department of Cartographic Engineering, Geodesy and Photogrammetry, Polytechnic University of Valencia, Spain. From 2005 to 2013, he directed the Faculty of Geodesy and Cartography at the Polytechnic University of Valencia. He is the author of 4 books and more than 40 articles. His research interest includes applied geophysics in civil engineering and cultural heritage and GPR research.

Prof. García has been a Member of the Society for Archaeological Prospection (ISAP) since 2003 and a Member of the Environmental and Engineering Geophysical Society EEGS- (Colorado, USA) since 1998. From 1993 to 2011, he was also an Associate Member of the Society of Exploration Geophysicists -SEG- (Tulsa, USA). From 2002 to 2005, he was the Coordinator of the Thematic Network EEGECS (European Education in Geodetic Engineering, Cartography and Surveying), a European Union-funded project (10427-CP1-2002-ES-ERASMUS-TN). And from 2000 to 2005, he was also the Assistant Secretary of the Applied Geophysics section in the Spanish Commission for Geodesy and Geophysics of the Ministry responsible for public works.

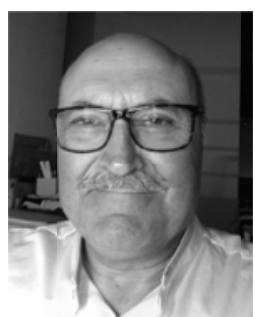

Manuel Ramírez was born in Jaén (Spain), in 1948. He received the B.S. degree in civil engineering, in 1983, the B.S. degree in architecture, in 1994 and the Ph.D. degree in architecture, in 1999 from the Polytechnic University of Valencia, Spain.

Since 1995, he has been a Lecturer with the Department of Architectural Constructions, Polytechnic University of Valencia. From 1996 to 2006, he was the Deputy Director of Forum UNESCO at the Valencian Central Office. He is the author of 30 books, more than 35 articles, and he holds a patent. His research interest includes architectural rehabilitation, NDT in architecture and safeguard of cultural heritage.

Dr. Ramírez's awards and honors include the Ph.D. Extraordinary Award from the Polytechnic University of Valencia and the first prize for the B.S. degree in architecture, in 1995 .

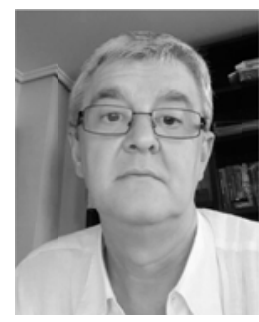

Javier Benlloch was born in Vitoria (Spain), in 1959. He received the B.S. degree in architecture, in 1984 and the $\mathrm{Ph} . \mathrm{D}$. degree in architecture, in 1987, from the Polytechnic University of Valencia, Spain.

Since 1996, he has been a Professor with the Department of Architectural Constructions, Polytechnic University of Valencia, Spain. From 1992 to 2008, he was the Director of the Department of Architectural Constructions at the Polytechnic University of Valencia. He is the author of more than 20 chapters of books and more than 20 articles, and he has leaded more than ten competitive research projects. His research interest includes NDT in concrete and wood, and cultural heritage. $\mathrm{He}$ is an Assistant Editor of the journal Informes de la Construcción. 